\title{
Product set granularity and consumer response to recommendations
}

\author{
Dimitrios Tsekouras $^{1} \cdot$ Benedict G. C. Dellaert ${ }^{2,3}$ (D) $\cdot$ Bas Donkers $^{2} \cdot$ Gerald Häubl $^{4}$
}

Received: 20 March 2018 / Accepted: 30 July 2019/Published online: 22 August 2019

(C) The Author(s) 2019

\begin{abstract}
Many consumer decisions are assisted by product recommendations. When retailers provide such recommendations, there is an inherent tension between (1) presenting a set of products that are close in attractiveness (fine product set granularity) and (2) presenting a wider range of products that are more different in attractiveness (coarse product set granularity). While the former can maximize the attractiveness of the recommended set of products, the latter makes it easier for consumers to determine which of the recommended products is most attractive, thus boosting consumer response. Evidence from a large-scale field study (with naturally occurring variation in the granularity of online recommendation sets) provides strong support for this tension and shows that less fine-grained product recommendation sets promote consumer response. We also find that, in line with our theorizing, coarser set granularity increases the time consumers spend processing detailed information about individual products relative to time they spend comparing products at the set level. These effects are less pronounced when consumer engagement in the decision process is low. The key insights from the field study are replicated in a tightly controlled experiment (using a different product domain). The findings of this research have important implications for how best to integrate large online assortments and product recommendations to stimulate consumer response.
\end{abstract}

Keywords Product recommendations · Product set granularity · Online assortments · Consumer response $\cdot$ Consumer decision-making

\section{Introduction}

For many online product decisions, consumers have access to a vast array of alternatives. Online retailers' assortments are typically very large, and product comparison sites even bring together products from multiple retailers and suppliers. These online firms often help consumers in making product decisions

J. Andrew Petersen served as Area Editor for this article.

Electronic supplementary material The online version of this article (https://doi.org/10.1007/s11747-019-00682-6) contains supplementary material, which is available to authorized users.

Dimitrios Tsekouras

dtsekouras@rsm.nl

Benedict G. C. Dellaert

dellaert@ese.eur.nl

Bas Donkers

donkers@ese.eur.nl

Gerald Häubl

gerald.haeubl@ualberta.ca by providing product recommendations in the form of a list of suitable alternatives (i.e., products meeting criteria that the consumer has specified) sorted in terms of one or more features relevant to the consumer (e.g., price). We refer to these product recommendation systems as explicit systems in that they clearly state their aim of matching products to consumers' preferences (Li and Karahanna 2015; Xiao and Benbasat 2007). They
1 Rotterdam School of Management, Department of Technology and Operations Management, Erasmus University Rotterdam, P.O. Box 1738, 3000, DR Rotterdam, The Netherlands

2 Erasmus School of Economics, Department of Business Economics, Marketing Section, Erasmus University Rotterdam, P.O. Box 1738, 3000, DR Rotterdam, The Netherlands

3 Department of Marketing, Monash Business School, Monash University, P.O. Box 197, Caulfield East, Victoria 3145, Australia

4 School of Business, University of Alberta, Edmonton, AB T6G 2R6, Canada 
are common in practice and have been studied both in marketing (Dellaert and Häubl 2012; Häubl and Murray 2003; Häubl and Trifts 2000) and information systems (Komiak and Benbasat 2006; Tam and Ho 2005).

An essential property of explicit product recommendation systems is that they screen and sort product assortments for the consumer. As a result, they reduce the need for consumers to search for high quality products, and they have been shown to improve consumer decision outcomes (Häubl and Trifts 2000; Li and Karahanna 2015). Firms also benefit from providing recommendations because the reduction in search effort can increase consumer response to product offerings. Typical target responses are sales (for deal-based business models, e.g., online retailers) or click-throughs to external vendors (for lead-based business models, e.g., product comparison websites). Analyzing whether or not consumers respond to a recommended set is essential for firms (Davis 2018) and is in line with previous research in decision making on consumer response to sets of different composition (Chernev 2005; Dhar 1997; Dhar and Nowlis 2004).

In this paper, we propose that even though consumers' need to search a large assortment is significantly reduced by product recommendations, they may still experience difficulty in selecting the most attractive alternative from a set. With the emergence of large online assortments, product differentiation has become increasingly fine-grained, resulting in smaller differences between competing products. As a result, it is often challenging for consumers to make product comparisons at the set level and decide which of the alternatives is the best for them (Dellaert et al. 2012; Shugan 1980). This increased difficulty of determining the best alternative due to the increased closeness in attractiveness between alternatives increases the likelihood of choice deferral and hence lowers consumer response (Chernev 2006; Dhar 1997; Dhar and Nowlis 2004). Paradoxically, this effect of large assortments on consumer decision making cannot be overcome - and may even be amplified - by product recommendations which tend to group alternatives that are very similar in attractiveness at the top of the recommended list.

We argue that there is an inherent tension for retailers when providing product recommendations to consumers, between the benefits of presenting those products that are closest in (high) predicted attractiveness (fine product set granularity) and presenting a wider range of products, different in predicted attractiveness (coarse product set granularity). Finer granularity causes the attractiveness of products in the recommendation list to decline less strongly, while coarser granularity leads to a greater decline in attractiveness. While the first approach maximizes the predicted attractiveness of the recommended set, we propose that the second strategy makes it easier for consumers to determine which product is the most attractive one to them and renders the desired consumer response (e.g., completing a purchase or requesting further information) more likely.

We propose a conceptual framework to explain how finer product set granularity reduces consumer response in large online assortments, despite the fact that the recommended top set of products is more attractive than in the case of coarser product set granularity. We test our predictions in two studies. We first analyze clickstream field data of a large sample of consumers who visited a financial product recommendation website. Next, we extend the generalizability of our findings in a controlled experiment in the context of consumer electronics (i.e., digital cameras). Using detailed information on variation in the products at the top of the recommendation list presented to each individual consumer, we show that finer product set granularity in recommended products (captured by the average difference in attractiveness among the alternatives in the top recommended set) decreases consumer response. We also provide insights into the behavioral mechanisms underlying consumer response using two timebased indicators of a consumer's decision process that are readily available to firms.

The current research contributes to the literature in three ways. First, while prior research has extensively addressed the potential (negative) impact of closeness in product attractiveness on consumer response (Chernev 2006; Dhar 1997), this is the first study to evidence this effect on consumer response in the field (Anderson 2003; Broniarczyk and Griffin 2014; Chernev et al. 2015). Thus, a key contribution of our paper is to demonstrate, using real-world field data, a behavioral effect of closeness in product attractiveness on consumer response. We show that consumers' response to recommendations is lower in fine-grained sets, despite the fact that these sets provides them with better products. Second, we provide insights into how consumers process recommendation sets to support the understanding of what drives the impact of finer product granularity on consumer response. While prior research on consumer response typically focuses on consumer information processing at a single layer of information only (Dhar 1996), we propose a conceptual model where product set granularity affects consumer response through two decision steps that are reflective of most retail websites. These steps are related to set- and product level information processing and represent directly observable behavioral indicators of the amount of information processing at the different layers of online shopping and recommendation websites. Thus, the framework allows us to investigate the behavioral impact of product granularity, using variables that are easily accessible to 
managers and the insights from our research have clear managerial implications also. We report the results of a simulation to illustrate how the insights from our study can be used to guide how firms can best combine large assortments and product recommendations to promote consumer response. Third, we provide evidence that the effect of finer product set granularity is moderated by the level of decision engagement of consumers. While more engaged consumers respond negatively to product sets with finer granularity, those who are less engaged are less sensitive to granularity differences.

\section{Product set granularity and consumer response to product recommendations}

We define product set granularity as the average difference in attractiveness between all pairs of products in an assortment that are adjacent (closest) in terms of product attractiveness. Finer product set granularity implies that the differences in attractiveness between adjacent alternatives in an assortment are smaller, while coarser product set granularity implies that these differences are larger. In assortments, fine product set granularity occurs when many different product variants are offered (e.g., many different sizes, brands). The reason is that when more and more product variants are introduced, more refined differences between products are made possible, and hence smaller differences in attractiveness arise from one product to the next.

With fine product set granularity, a randomly presented list of alternatives can still produce considerable differences in attractiveness from one alternative to the next. However, when recommendation lists are offered, the sorting of alternatives in terms of product attractiveness inherently presents consumers with more similar alternatives at the top of the recommendation list when product set granularity is fine than when it is coarse. In this research, we address the question of how finer (vs. coarser) product set granularity affects consumers' response to recommendations. More specifically, we address explicit product recommendation systems that provide consumers with a list of products that are sorted in terms of one or more attributes (e.g., price) of relevance to the consumer (Häubl and Trifts 2000; Xiao and Benbasat 2007).

Research has shown that these product recommendation lists help consumers by reducing the search effort needed to find high quality alternatives (Häubl and Trifts 2000; Li and Karahanna 2015). As a result, recommendation lists improve the quality of consumer decisions (Diehl et al. 2003; Häubl and Trifts 2000; Xiao and Benbasat 2007), which also increases consumer satisfaction and loyalty (Liang et al. 2006). The fact that product recommendation lists present consumers with a sorted list of the most attractive products is of particular importance in relation to the level of product granularity of assortments. Because of this presentation format, recommended products are likely to be close in attractiveness, making the top set of products more attractive to consumers than if no sorting were available. When product granularity becomes more fine-grained, this attractiveness of the top set of recommended products increases further, because the distance in attractiveness between the most highly recommended product and the subsequent products becomes smaller. Thus, finer product granularity further increases the attractiveness of the top set of recommended products, because consumers now see a more attractive set of products at the top of the recommendation list.

Normatively, this more attractive top set of products should also make it more likely for consumers to respond to the firm's offer by choosing one of the products in the recommended set. However, we propose that, behaviorally, a consequence of finer product set granularity is that it is more challenging for consumers to identify their preferred alternative from the top of the recommended set (Chatterjee and Heath 1996; Dellaert et al. 2012; Liberman and Förster 2006). The difficulty of choosing among more similar products requires consumers to engage in more effortful decision strategies to choose the best alternative from the set of top alternatives (Bettman et al. 1993; Johnson et al. 1989; Klein and Yadav 1989). This effort requirement is likely to demotivate the consumer to decide, and may even exceed the potential positive effects of choosing from a set of attractive alternatives (Dhar 1996; Fasolo et al. 2009; Tyebjee 1979).

Therefore, we propose that finer product set granularity (smaller differences in terms of product attractiveness from one alternative to the next) reduces consumer response to product recommendation lists. Conversely, coarser product set granularity should facilitate consumer response as it allows consumers to more easily determine which of the products is most attractive (Dellaert and Häubl 2012; Dhar 1997; Liberman and Förster 2006). With coarser product set granularity, consumers can also more easily perceive that the best product they encountered is more attractive than the more inferior alternatives they have seen and which serve as reference points (Janiszewski and Lichtenstein 1999; Mellers 2000).

\section{The mediating role of product relative to set level information processing}

The predicted negative effect of finer product set granularity on consumer response suggests a psychological mechanism governed by the ease of identifying the most attractive product in a recommendation set as well as the perceived attractiveness of this product. To investigate this mechanism more explicitly, we use as behavioral indicators of information processing time the amount of time that consumers engage with 
information about the recommended products, as is common in prior work on decision difficulty (Fischer et al. 2000; Jacoby et al. 1976; Payne et al. 1988). In particular, we analyze the time consumers spent processing information (1) at the level of the set of top alternatives in the product recommendation list and (2) at the level of individual products, one at a time. Such a decision environment is common in commercial websites and highlights the tension between comparing and investigating product related information. We predict that the effect of finer product set granularity influences the relative allocation of consumer processing time across the two information layers, which in turn influences consumer response.

We propose that consumers follow a process by which they (1) identify in a recommended set which products are worth inspecting in greater detail and (2) determine, for each product that they inspect in detail, if they should request a quote (field study) or make a purchase decision (experiment). In this process, we hypothesize that as closeness in attractiveness increases (i.e., with finer product set granularity), consumers will need more time to identify which product is sufficiently attractive to warrant further detailed inspection. This increase in time is due to the greater number of comparisons consumers will need to make between products when they are more similar to be able to identify the most attractive one(s) for further inspection (Busemeyer and Townsend 1993; Moyer and Bayer 1976; Shugan 1980). With coarser product set granularity, the inclusion of less attractive alternatives near the top of the recommendation list facilitates this identification process because it increases the perceived attractiveness of the best alternatives as they stand out more clearly from the less attractive ones (Janiszewski and Lichtenstein 1999; Mellers 2000). Thus, the number of comparisons increases nonlinearly with finer product granularity and more products become candidates for detailed inspection.

Additionally, we predict that the number of products that consumers inspect in detail will increase at a much smaller rate than the number of comparisons, even when many candidates are available. The reason for this second prediction is twofold. First, the number of products in a set only increases linearly, while the number of comparisons increases non-linearly. Second, behaviorally, the additional effort of having to click through to the next level of inspection will likely disproportionally affect detailed product inspection more strongly than set level inspection (Häubl et al. 2010). Thus, we anticipate that the increase in product inspections with finer product granularity will dampened due to the additional (behavioral) cost of inspection.

Consumers' information processing of recommended products logically precedes their response to product recommendations. Our theorizing about why finer product set granularity decreases consumer response to these lists implies that this effect is mediated by how consumers engage with the information about the recommended products. Therefore, we propose that the ratio of the time spent processing information at the product level over the total time of product plus set level processing mediates the effect of finer product set granularity predicted on consumer response. Such a measure of relative time spent has been previously implemented in the context of consumer decision strategies (Riedl et al. 2008). Figure 1 illustrates the behavioral mechanism for the impact of finer product set granularity on consumer response.

\section{Study 1: Field evidence}

The empirical analysis for our field study is based on clickstream data from a leading recommendation website for financial products in the Netherlands. The website serves as an intermediary between consumers and financial institutions. The data capture consumers' online product inspection and choice behavior in connection with home mortgages. Mortgages are a suitable domain for our research because consumers tend to make careful decisions when choosing their mortgage (Huang et al. 2009), yet still benefit from product recommendations to help them find a suitable product in a complex market with many different alternatives.

We obtained 2 mon of clickstream data and analyzed a total of 9330 visits to the recommendation website that occurred during this period. ${ }^{1}$ For each visit, the top alternatives in the recommendation list (i.e., the most attractive recommended products), ${ }^{2}$ the user's individual characteristics, his/her desired mortgage specifications, clickstream data capturing his/ her set level and product level processing, and any requests for quotes were recorded. On $74.3 \%$ of the visits, at least one alternative was inspected in detail. The average number of products inspected on a visit was 1.17. A mortgage quote was requested on $27.2 \%$ of the visits. The average annual gross income of the consumers using the recommendation website was 43,485 euros, and the average mortgage required

\footnotetext{
${ }^{1}$ Only visits during which a user proceeded to the point where a recommendation was provided were included in the analysis. We also included only visits in which a single product recommendation set was obtained. Finally, we included only visits with decision times that fell within realistically feasible lower and upper limits (i.e., a minimum of $10 \mathrm{~s}$ of set level processing and at most 30 min of inactivity during the visit) (Moe 2003).

${ }^{2}$ The website collected information about the first nine products of each recommended set, all of which were displayed on a single page. The firm uses a conjoint style task that is offered to internal experts to provide expert advice to rank the quality of different mortgage products. Based on the estimated weights applied by these experts in their decisions, the balanced ranking is made. This approach is taken because expert judgments are deemed to be a more accurate source of product quality information, and hence a preferred basis for providing recommendations, than e.g., an algorithm based on consumers' own mortgage choices. Given that no information beyond the consumer provided characteristics (and the internal quality ratings) are used to feed the recommender system the same recommendation rules apply to all consumers.
} 


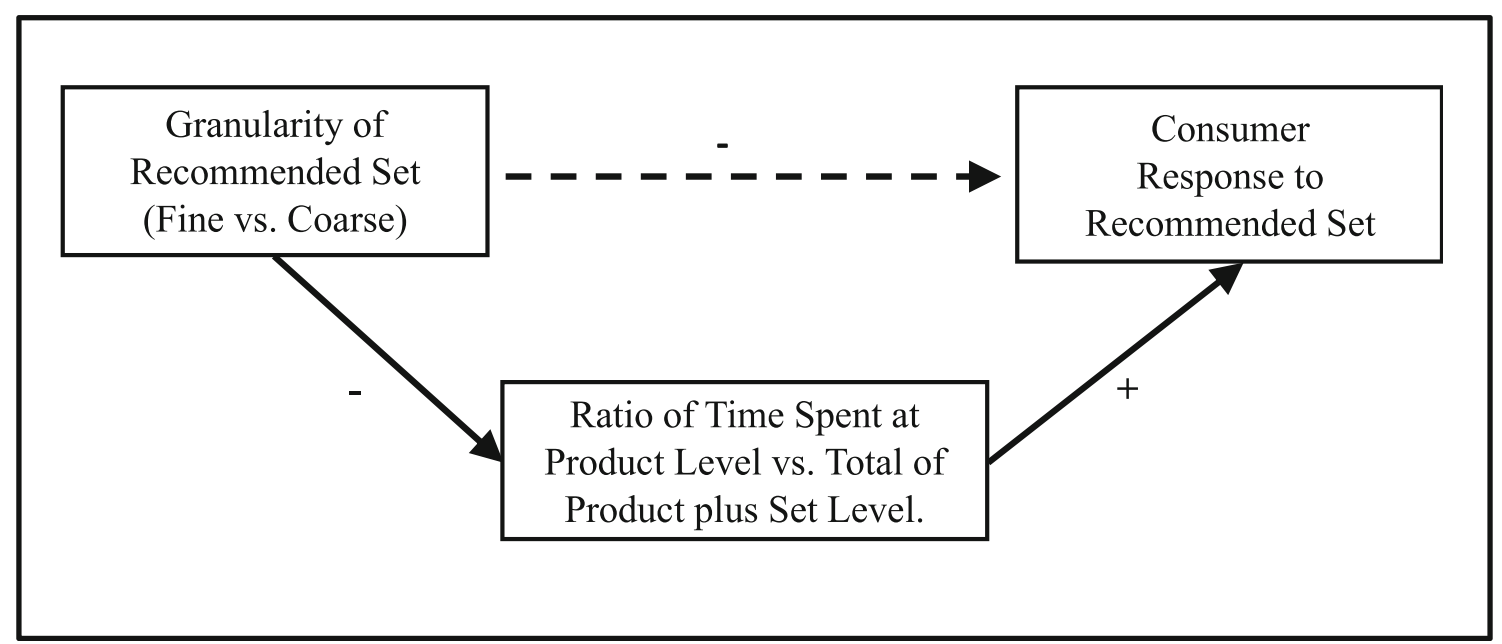

Fig. 1 Conceptual model

was 223,202 euros - both are representative of the mortgage market in the Netherlands at the time. We provide an overview of the descriptive statistics in Appendix Table 4.

Users of the website entered their desired mortgage specifications-mortgage type, ${ }^{3}$ mortgage amount, and initial term of fixed interest rate (e.g., 5 years)-along with several individual characteristics (current personal bank, annual income). Based on this information, they were presented with a list of recommended mortgage products. This list presented the alternatives that matched the consumer's specifications sorted (in ascending order) by interest rate, which is the most critical attribute when choosing a mortgage product (Devlin 2002; Laroche and Taylor 1988). The description of each alternative consisted of the name of the firm providing the mortgage, along with the administrative fee for closing the mortgage and two rating scores (a website's rating of the mortgage product and rating of the mortgage provider by its current clients).

For each product on the list, consumers were able to click to inspect a more detailed description, which was then presented on a separate screen. Consumers were able to request a quote from the mortgage provider via the recommendation website. The final part of the transaction (i.e., the signing of the mortgage contract) was completed directly between the consumer and the mortgage provider. The recommendation website earns a fee per lead (i.e., request of a mortgage quote) paid by the firm receiving the lead. We use the request of a mortgage quote as our dependent variable of a positive consumer response to the product recommendation list-i.e., the desired consumer outcome from the website's standpoint.

\footnotetext{
${ }^{3}$ The available mortgage types were (1) combined savings and interest-based mortgages, (2) interest-only mortgages, and (3) annuity mortgages.
}

\section{Measures}

Product set attractiveness We use three separate measures for set attractiveness, based on the most attractive value for each of the three attributes accessible at the set page. Interest rates are the most critical component in a mortgage choice (Devlin 2002; Laroche and Taylor 1988), and past studies have shown that most prospective borrowers spend most of their time searching for and comparing interest rates (Lee and Hogarth 1999). Further, market-oriented studies have shown that interest rate are the most important attributes regarding a mortgage choice (National Mortgage Database 2016). For the interest rate we use the lowest value in the set (i.e., that of the first recommended product) as our measure of product set attractiveness. This value is multiplied by minus 1 to reflect that lower interest rates are more attractive. To capture additional product attributes that influence a mortgage attractiveness, we measure two additional attributes accessible in the product set page; product rating and provider rating. The product rating is based on the website's expert evaluation of the quality of a mortgage product ( 1 to 5 stars) and the provider rating is based on customers' reviews of the mortgage product provider (1 to 10 scale). We use the highest ratings in the product set to capture attractiveness on these dimensions.

Product set granularity We quantify product set granularity as the average difference in attractiveness (for interest rate, product rating and provider rating) between the alternatives in the recommendation list. The smaller this average difference in attractiveness, the finer product set granularity is. It is calculated as $-1 *$ (best value - worst value) / (number of products), where we use the multiplication with -1 so that high numbers depict finer product set granularity. The field data we obtained contain information about the first nine products of the recommendation list; hence, we determine product set granularity based on these products. 
Consumer response We operationalize consumer response as a binary variable that captures whether a consumer's visit to the recommendation website culminated in the request of a mortgage quote. This operationalization is in accordance with the business model of the website since it is based on a fee per lead (i.e., request of a mortgage quote) paid by the firm receiving the lead.

Processing time In line with our conceptual model, we distinguish between set level and product level processing in the amount of time a consumer spent processing information about the recommended products. Set level processing is measured as the total time spent on the page displaying the set of recommended mortgage products. Product level processing is measured as the total time spent on pages with detailed information about each individual product. The inputs for these time-based measures are the observed time differences between consecutive page requests. Since duration data are left truncated (i.e., non-negative) and right skewed, we log transformed all time measures in line with standard practice (Bucklin and Sismeiro 2003; Johnson et al. 2003). ${ }^{4}$ The transformed variables are approximately normally distributed. A challenge associated with clickstream data is that the duration of the last page view of a visit is unobservable since the time when a user exits the website can typically not be recorded (Sismeiro and Bucklin 2004). However, when the last recorded event was a product level inspection, we include this in TimeProduct by imputing the average product inspection time for the unobserved value. We calculate the ratio of product time (Ratio Product Time) over the total time spent on these two types of pages.

Additional variables For robustness and to more accurately estimate the impact of the variables of substantive interest, we estimate our model including a number of control variables that capture properties of the set of alternatives and the consumers. We provide an overview of these variables in Appendix 2.

\section{Correcting for consumer input-based sources of variation in product set granularity}

Our theoretical framework focuses on the impact of product set granularity on consumer response to product recommendation lists. In the field data, variation in product set granularity arises from two sources: (1) the consumer's own input and (2) the market dynamics in the available alternatives that were exogenous to the consumer choice. Inherently, as a first source of variation, the composition of the list of recommended products varied as a function of the desired mortgage specifications entered by a consumer. This generated variations in product

\footnotetext{
4 To be able to include visits during which no product level processing occurred, we added one second to TimeProduct and each of the other time measures before the log transformation.
}

set granularity between consumers, for example because some product specifications corresponded to a greater number of products that were available in the market than others. Next, mortgage providers also varied their products' characteristics (such as interest rates offered) in response to economic factors and competitors' concurrent offerings. This second source also generates differences in the product set granularity of the list of recommended products across consumers. Since we cannot rule out the possibility that for the first source of variation (consumer input) the composition of the recommendation list and consumer response to these recommendations might be influenced by a common unobservable variable, we control for this source of variation in our analysis to remove the possible endogeneity bias associated with it.

More specifically, we separate the potentially endogenous variation in the product set granularity from the exogenous variation that is present. To do this, we model all properties of the recommended set as a function of the specifications entered by the consumer (see Web Appendix A for the detailed models). The residuals of these models characterize the properties of the set that cannot be explained by the consumer's input, thus capturing the impact of independent variation in the market, which is exogenous to the consumer's preexisting propensity to respond to the recommendation. Hence, similar to the two-stage residual inclusion (2SRI) method (Terza et al. 2008), we include both the endogenous and the residual exogenous components of product set granularity. As we use a nonlinear model for conversion, consistency can only be achieved by including both components, while traditional 2SLS, which only includes the exogenous component, would result in inconsistent estimates (Terza et al. 2008). Our approach is similar in spirit to the control function approach (Petrin and Train 2010), but differs because usually one has access to exogenous regressors with a possibly endogenous error term, while in our situation there is possible endogeneity in the regressors that we wish to account for. As the residuals of the regressions, which are driven by variation in market conditions after controlling for mortgage specifications, capture the exogenous variation in product set granularity, we use the coefficients on these residuals to test our expected effects. The 2SRI estimator that we apply has already been successfully applied in marketing (Shen and Xiao 2014; Danaher et al. 2015), see also the review on endogeneity in marketing models by Papies et al. (2017).

\section{Models}

Consumer response model We examine the consumer's decision to request a mortgage quote via the recommendation website. This model predicts the probability of consumer response during a visit to the website. We use a logit model to characterize the consumer's decision to request a quote for a mortgage product from the recommendation list (Consumer 
Response $=1)$ or not $(=0)$ as a function of product set granularity. To indicate that we use the (exogenous) residuals for various independent variables in our analysis, these variables are denoted with a superscript (R). We include both a linear and a quadratic term for granularity measures to allow for potential non-linearity in the expected effects. In all models we include the other product variables listed under measures and the set of control variables, but these are not included in detail in the equations below for expositional clarity.

$$
\begin{aligned}
& P\left(\text { ConsumerResponse }_{i}=1\right)=\frac{\exp \left(V_{i}\right)}{1+\exp \left(V_{i}\right)} \\
& V_{i}=\beta_{0}+\beta_{1} \text { InterestRateAttractiveness }_{\mathrm{i}}{ }^{(\mathrm{R})}+\beta_{2} \text { InterestRateGranularity }_{\mathrm{i}}{ }^{(\mathrm{R})}+ \\
& \beta_{3} \text { ProductRatingAttractiveness }_{\mathrm{i}}{ }^{\mathrm{R})}+\beta_{4} \text { ProductRatingGranularity }_{\mathrm{i}}{ }^{(\mathrm{R})}+ \\
& \beta_{5} \text { ProviderRatingAttractiveness }_{\mathrm{i}}{ }^{\mathrm{R})}+\beta_{6} \text { ProviderRatingGranularity }_{\mathrm{i}}{ }^{(\mathrm{R})}+\text { Controls }^{\mathrm{R}}
\end{aligned}
$$

Processing time model We model the ratio of product level processing (RatioProductSet), on product set granularity and attractiveness, and other properties of the recommended set. The error term $\left(\zeta_{\mathrm{i}}\right)$ is assumed to be normally distributed.

RatioProductTime $_{\mathrm{i}}=\gamma_{0}+\gamma_{1}$ InterestRateAttractiveness $_{\mathrm{i}}{ }^{(\mathrm{R})}+$ $\gamma_{2}$ InterestRateGranularity $_{i}{ }^{(\mathrm{R})}+\gamma_{3}$ ProductRatingAttractiveness $_{\mathrm{i}}{ }^{(\mathrm{R})}+$ $\gamma_{4}$ ProductRatingGranularity $_{i}{ }^{(\mathrm{R})}+\gamma_{5}$ ProviderRatingAttractiveness $_{\mathrm{i}}{ }^{(\mathrm{R})}+$ $\gamma_{6}$ ProviderRatingGranularity $_{i}^{(\mathrm{R})}+$ Controls $+\zeta_{\mathrm{i}}$

\section{Results}

We first examine the effect of finer product set granularity in the recommendation list on consumer response (Table 1, Column 1). As anticipated, interest rate was the strongest determinant of consumer response. The results show that, as predicted, for interest rate a finer product set granularity has a significant negative effect on consumer response to recommendations $\left(\beta_{2}=-7.56, p<0.05\right)$. Also, as expected, the baseline effect of attractiveness of the recommendation list on consumer response is positive $\left(\beta_{1}=0.58, p<0.05\right)$. The effects of product and provider rating attractiveness are not significant. This result can be explained by the fact that interest rate is the most important attribute in decision-making in the context of home mortgages and the ranking is also based on interest rate.

Next, we shed light onto the behavioral mechanisms underlying the effect of the product set granularity on consumer response by examining the ratio of product level processing i.e., the amount of time consumers spent processing information at the level of individual products, over the total time spent in the session. We expected that finer product set granularity decreases the ratio of product level processing and consumers are less likely to inspect alternatives in detail. We find that finer product set granularity does have a significant negative effect on the ratio of time spent processing detailed information about alternatives $\left(\gamma_{2}=-1.21, p<0.05\right)$.

To test the expected pathway based on our conceptual framework, i.e., finer product set granularity in a recommendation list influences consumer response to recommendations via the ratio of product level processing of information over the total time spent at the product and set level in a session, we conduct a mediation analysis (Zhao et al. 2010). We find that, in line with our prediction, the ratio of product level information processing time has a positive effect on the probability of consumer response $\left(\beta_{\text {Ratio Product Time }}=2.43, p<0.01\right)$ (Table 1, Column 3). The estimation results show that the effect of a finer interest rate granularity is no longer significant once the ratio of product level processing time is included in the model. This provides support for the predicted mediation effect. The effect is robust when we control for the total time spent. We run a bootstrap analysis (Hayes 2012; Pieters 2017; Zhao et al. 2010) to conduct a more rigorous mediation test. ${ }^{5}$ The focus of this analysis is on interest rate granularity in line with our preliminary findings above. We report unstandardized coefficients. The results further support our predicted effects. We find a significant total indirect effect of finer interest rate granularity (effect $=-2.99$; $\mathrm{se}=1.05 ; \mathrm{LB}:-5.09$; UB: 0.93). This finding demonstrates that the negative indirect effect through product level processing is due to the fact that finer product set granularity decreases the ratio of product level information processing, which in turn also decreases consumer response.

\section{The moderating effect of decision engagement}

Prior research suggests that for consumers who are less engaged in the decision process, attribute information in a choice set is less meaningful and less likely to drive their information processing approach. These consumers have less well-defined product preferences and therefore are less likely to be influenced by product set attribute differences (Ratneshwar et al. 1987). Once consumers become more engaged in the decision process, they form clear preferences and they become more goal directed in their information processing (Moe 2003). As a result, consumers who are more engaged in a decision are likely to be more susceptible to the effect of finer product set granularity. Conversely, we expect that with lower decision engagement consumers will process choice set cues more superficially and (have less knowledge about alternatives. Therefore, we expect that they will be less sensitive to product

\footnotetext{
$\overline{{ }^{5} N=9330 ; 5000}$ bootstrapped samples; Unstandardized coefficients are shown; LL is lower level, and UL is upper level of $95 \%$ confidence interval.
} 


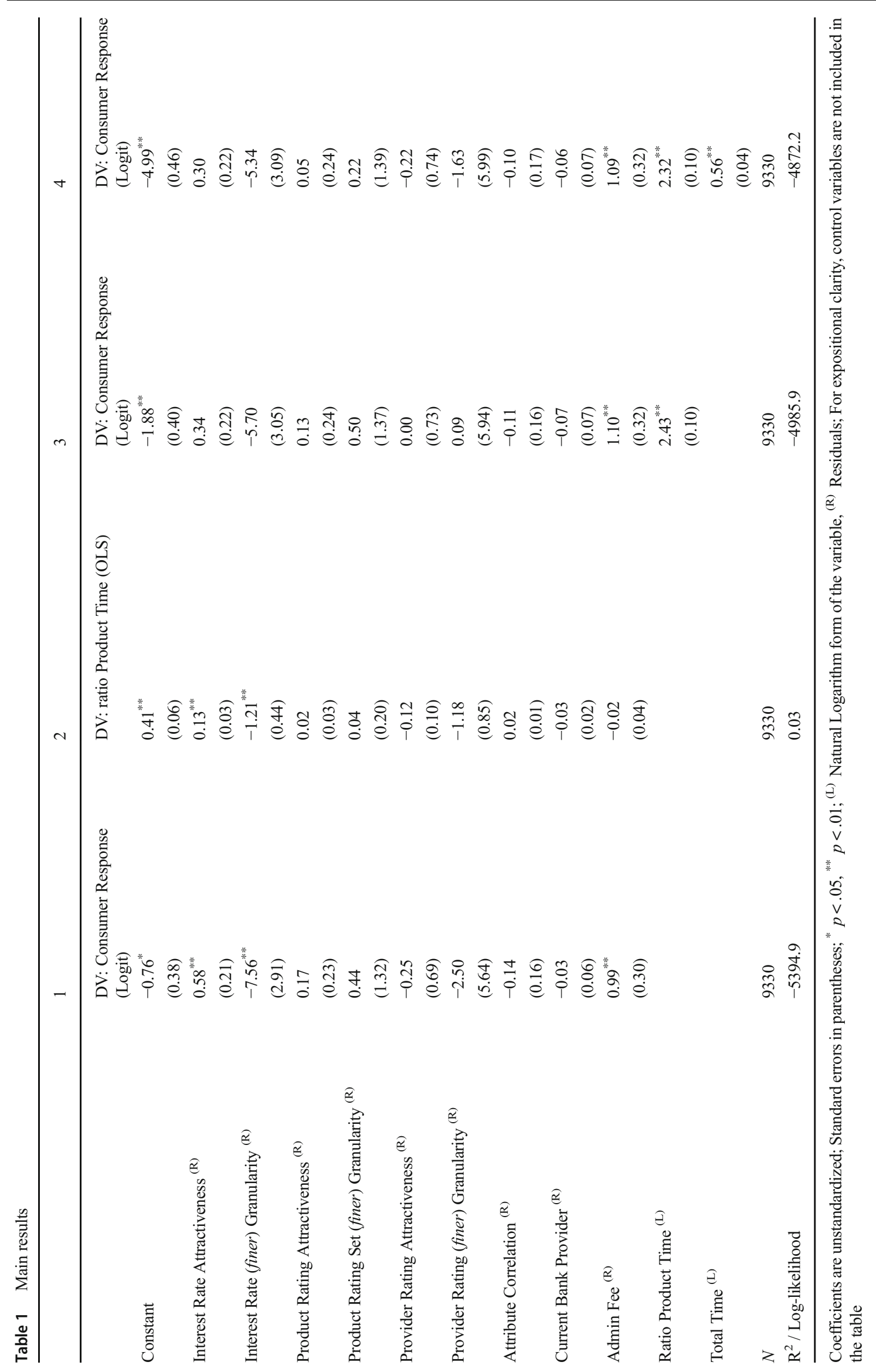


granularity differences (Bettman and Park 1980). This theorizing is also in line with the concept of a purchase funnel and how consumer advancement in the purchase funnel relates to information processing (Bettman et al. 1998).

To investigate if our findings are affected by the level of consumer engagement in the decision process, we identify consumer engagement in the decision in the following way. When consumers entered the website, they were asked to specify the amount of the desired mortgage, their income and the period of fixed interest rate. However, these answers were not mandatory and they could also skip them. We identify consumers who do not fill the above information as less engaged in the decision process. Further, we identified a dummy variable called decision engagement as high when consumers filled all the personal information and low otherwise. We conducted subsample analyses and found that the identified effects of product set granularity on consumer response is significant for consumers that had filled information about the amount, income and period of fixed rate (Table 2).
We also analyzed the models including interaction effects with engagement These analyses show that the direct effects remain robust whereas the interaction effects are not significant. Thus, we conclude that the results in our field data are directionally indicative of a moderating effect of decision engagement, but do not provide statistical support for the anticipated effect. We anticipate that due to the high engagement context of mortgages on the website for our field data, most consumers can be considered as highly engaged with the decision. We further address the potential moderating effect of consumer decision engagement in an experimental study on consumer electronics.

\section{Robustness analyses}

In the interest of rigor, we also conducted a series of robustness analyses to further establish the validity of our results. These tests include investigating the heterogeneity of results across product set features and financial characteristics, different operationalizations of
Table 2 Moderation: Decision engagement

\begin{tabular}{|c|c|c|}
\hline & 1 & 2 \\
\hline & \multicolumn{2}{|c|}{ DV: Consumer Response (Logit) } \\
\hline & Engagement (low) & Engagement (high) \\
\hline \multirow[t]{2}{*}{ Constant } & $-2.25^{*}$ & 0.68 \\
\hline & $(0.95)$ & $(0.65)$ \\
\hline \multirow[t]{2}{*}{ Interest Rate Attractiveness ${ }^{(\mathrm{R})}$} & 0.26 & $0.67^{* *}$ \\
\hline & $(0.76)$ & $(0.22)$ \\
\hline \multirow[t]{2}{*}{ Interest Rate (finer) Granularity ${ }^{(\mathrm{R})}$} & -7.53 & $-7.15^{*}$ \\
\hline & $(8.34)$ & $(3.18)$ \\
\hline \multirow[t]{2}{*}{ Product Rating Attractiveness ${ }^{(\mathrm{R})}$} & -0.70 & 0.27 \\
\hline & $(0.60)$ & $(0.25)$ \\
\hline \multirow[t]{2}{*}{ Product Rating Set (finer) Granularity ${ }^{(\mathrm{R})}$} & -5.60 & 1.42 \\
\hline & $(3.80)$ & $(1.42)$ \\
\hline \multirow[t]{2}{*}{ Provider Rating Attractiveness ${ }^{(\mathrm{R})}$} & -1.17 & -0.18 \\
\hline & $(1.88)$ & $(0.76)$ \\
\hline \multirow[t]{2}{*}{ Provider Rating (finer) Granularity ${ }^{(\mathrm{R})}$} & -9.93 & -2.05 \\
\hline & $(14.93)$ & $(6.26)$ \\
\hline \multirow[t]{2}{*}{ Attribute Correlation ${ }^{(\mathrm{R})}$} & 0.02 & -0.17 \\
\hline & $(0.46)$ & $(0.17)$ \\
\hline \multirow[t]{2}{*}{ Current Bank Provider ${ }^{(\mathrm{R})}$} & 0.09 & -0.07 \\
\hline & $(0.14)$ & $(0.07)$ \\
\hline \multirow[t]{2}{*}{ Admin Fee ${ }^{(\mathrm{R})}$} & $3.37^{* *}$ & 0.63 \\
\hline & $(0.85)$ & $(0.33)$ \\
\hline$N$ & 1726 & 7593 \\
\hline Log-likelihood & -965.9 & -4384.1 \\
\hline
\end{tabular}

Coefficients are unstandardized; Standard errors in parentheses; ${ }^{*} p<.05,{ }^{* *} p<.01$; ${ }^{(\mathrm{L})}$ Natural Logarithm form of the variable, ${ }^{(\mathrm{R})}$ Residuals; ${ }^{\#}$ There were only 48 cases where no income was disclosed; For expositional clarity, control variables are not included in the table; For an additional subset analysis per variable, see Web Appendix B 
granularity and time ratio variables as well as alternative model specifications (see Web Appendix C). We find that the results are robust to different levels of product attribute skewness and kurtosis of the recommended set, as well as to the level of product set attractiveness and interattribute trade-offs. Further, the results are robust to (a) the presence of a consumer's bank in the set, (b) the amount of the mortgage and (c) the consumer's income. We also tested the robustness of the findings to different operationalizations of the product set granularity and time processing variables, and to different model specifications. The results are robust to these changes. Finally, the effects are robust when we considered the concentration of processing time across the products in the recommended set.

\section{Study 2: Experiment}

The analysis based on the field study provides us with evidence on the negative effect of finer product granularity on consumer response. To further provide evidence on the generalizability of these findings beyond the context of financial products, we conducted a controlled experiment in a different product context: consumer electronics (digital cameras). The choice of the product category serves two generalization purposes. First, digital cameras are products that do not have a single prevalent attribute as is the case with mortgages (i.e., interest rate). Thus, closeness in attractiveness may be harder to determine for consumers. Second, mortgage choices are a typical high engagement decision and the analysis in the field study suggested that the effect of finer granularity is present for consumers who are highly engaged with the decision process, but not for less engaged consumers. Therefore, we study the proposed conceptual model in a category where consumers vary more strongly in terms of decision engagement.

We developed a web-based environment that simulated the structure of the website in the field study for a consumer digital camera purchase decision. We randomly assigned respondents to a fine vs coarse product recommendation set granularity condition. Respondents could either choose to purchase a digital camera from a set of 10 recommended cameras or postpone that decision and we operationalized consumer response as this binary decision outcome. To simulate the field study, we allowed respondents to navigate between set level and product level pages before deciding. Accordingly, we measured the ratio of product time over the total time spent on these two types of pages (See Web Appendix $\mathrm{D}$ for a detailed overview of the study).
We recruited respondents via Amazon Mechanical Turk (AMT). We excluded respondents who failed attention checks, spent an extremely large amount of time on the study (upper 5\%), or with duplicate IP addresses. The final sample $(N=399)$ consisted of $56.9 \%$ males, $71.4 \%$ of respondents were between 25 and 44 years old, and $77.4 \%$ had obtained an undergraduate or higher degree. Respondents in the two conditions were statistically indistinguishable in terms of decision engagement variables and demographic characteristics (see Web Appendix D).

Following the indicative field evidence suggesting a moderating role of consumer engagement with the decision process, we created a decision engagement dummy indicator variable. To do so we first conducted a median split to separate respondents in high and low decision engagement on each of their answers regarding their level of familiarity, previous knowledge, and interest in digital cameras (Mantel and Kardes 1999). The decision engagement indicator variable then took the value of 1 when respondents had previous experience with buying a digital camera, and also belonged to the high level group for all the above variables. The indicator variable took a value of 0 otherwise. Following this approach, $57.6 \%$ of respondents were qualified as highly engaged in the decision.

We examined the effect of fine granularity on consumer response for the subset of highly engaged respondents and further investigated whether engagement with the decision process moderates the effect of granularity. For the highly engaged group of consumers, we replicate the field evidence regarding the effect of finer granularity (Table 3 ). Finer granularity decreases consumer response $(\beta=-0.79, p<0.05)$ and the ratio of product level information processing time $(\beta=-0.05, p<0.05)$. Further the ratio of product level information processing mediates the effect of product set granularity. A bootstrap analysis (Hayes 2012) showed a significant total indirect effect of finer interest rate granularity (effect $=-0.24$; se $=0.14$; LB: 0.60 ; UB: -0.02$)$. The results remain robust when we control for consumer demographics. We also examined the moderating effect of decision engagement for both high and low engagement groups and find a negative moderating effect of engagement on finer product granularity as expected $(\beta=-1.54, p<0.05$, see Appendix 3).

In summary, the purpose of the experimental study is to provide further evidence on the generalizability of the effect of product set granularity in a controlled setting and beyond the context of financial products. Thus, we demonstrate a negative effect of finer product set granularity on consumer response that is 
Table 3 Study 2 results: High decision engagement respondents

(1)

\begin{tabular}{|c|c|c|c|}
\hline & DV: Consumer Response (Logit) & DV: Ratio Product Time (OLS) & DV: Consumer Response (Logit) \\
\hline \multirow[t]{2}{*}{ Constant } & $2.27^{* *}$ & $0.58^{* *}$ & -0.79 \\
\hline & $(0.32)$ & $(0.02)$ & $(1.02)$ \\
\hline \multirow[t]{2}{*}{ (finer) Granularity } & $-0.79^{*}$ & $-0.05^{*}$ & -0.64 \\
\hline & $(0.40)$ & $(0.02)$ & $(0.43)$ \\
\hline \multirow[t]{2}{*}{ Ratio $\left(\right.$ TimeProduct ${ }^{(\mathrm{L})} /\left(\right.$ Time $\left.(\text { Set }+ \text { Product })^{(\mathrm{L})}\right)$} & & & $4.43^{* *}$ \\
\hline & & & $(1.00)$ \\
\hline \multirow[t]{2}{*}{ TimeTotal $^{(\mathrm{L})}$} & & & 0.20 \\
\hline & & & $(0.23)$ \\
\hline$N$ & 230 & 230 & 230 \\
\hline Log likelihood / $\mathrm{R}^{2}$ & -90.73 & 0.02 & -79.78 \\
\hline
\end{tabular}

Coefficients are unstandardized; Standard errors in parentheses; ${ }^{*} p<.05,{ }^{* *} p<.01$; ${ }^{(\mathrm{L})}$ Natural Logarithm form of the variable; Results remain robust when we control for consumer demographics

mediated by the ratio of product level processing time over the total of product and set level processing time. We further demonstrate that this process occurs for respondents who are highly engaged in the decision process.

\section{General discussion}

Product recommendations assist users in identifying better products in large assortments, thus improving the accuracy of their decisions (Häubl and Trifts 2000; Xiao and Benbasat 2007). In this research, we study field data from a prevalent type of recommendation system based on user-provided information over desired product specifications. These systems allow firms to present only the products that are relevant for a user and sort them according to a helpful criterion (e.g., lowest price, or in our case, lowest interest rate). Common intuition, in line with normative models of consumer decision making, would suggest that to maximize consumer response to product recommendations firms should include the subset of most attractive alternatives at the top of the list of products they recommend. This approach is also evident in practice, where many recommendation systems present users with rather homogenous and similarly attractive options ( $\mathrm{Li}$ and Karahanna 2015).

We examine how consumer response to recommendations depends on the degree of granularity of the recommended products when alternatives are presented in a list of descending order, as is typically the case in recommendation lists (Diehl and Zauberman 2005; Häubl and Trifts 2000). The research presented here challenges this intuition by showing that consumer response to recommendations may benefit from presenting them with product assortments that are less, not more, fine-grained. In particular, we find that, when controlling for the most attractive recommended product, finer product granularity in the top recommended products (constituting a more attractive set of recommended alternatives) decreases the probability of consumer response.

\section{Managerial implications}

Our findings have clear managerial implications for how to compose the product granularity of recommendation sets to promote consumer response. Product recommendation websites typically aim to present the best alternatives available. In doing so, they offer consumers a truncated set of products that are inherently similar in terms of attractiveness. However, with finer product granularity, these recommended alternatives are closer in terms of attractiveness, which may increase the choice difficulty that consumers experience. We find that this reduces the probability of consumer response.

To illustrate the managerial implications, we present a set of simulation analyses that reveal how consumer response is affected by different levels of product set granularity compared to changes in the attractiveness of the top alternative in a recommendation list. Figure 2 shows the effects of (1) finer product set granularity in a set and (2) the attractiveness of this set on consumer response. It is clear that product set granularity has an impact that is comparable in size to that of the attractiveness of the set, in terms 


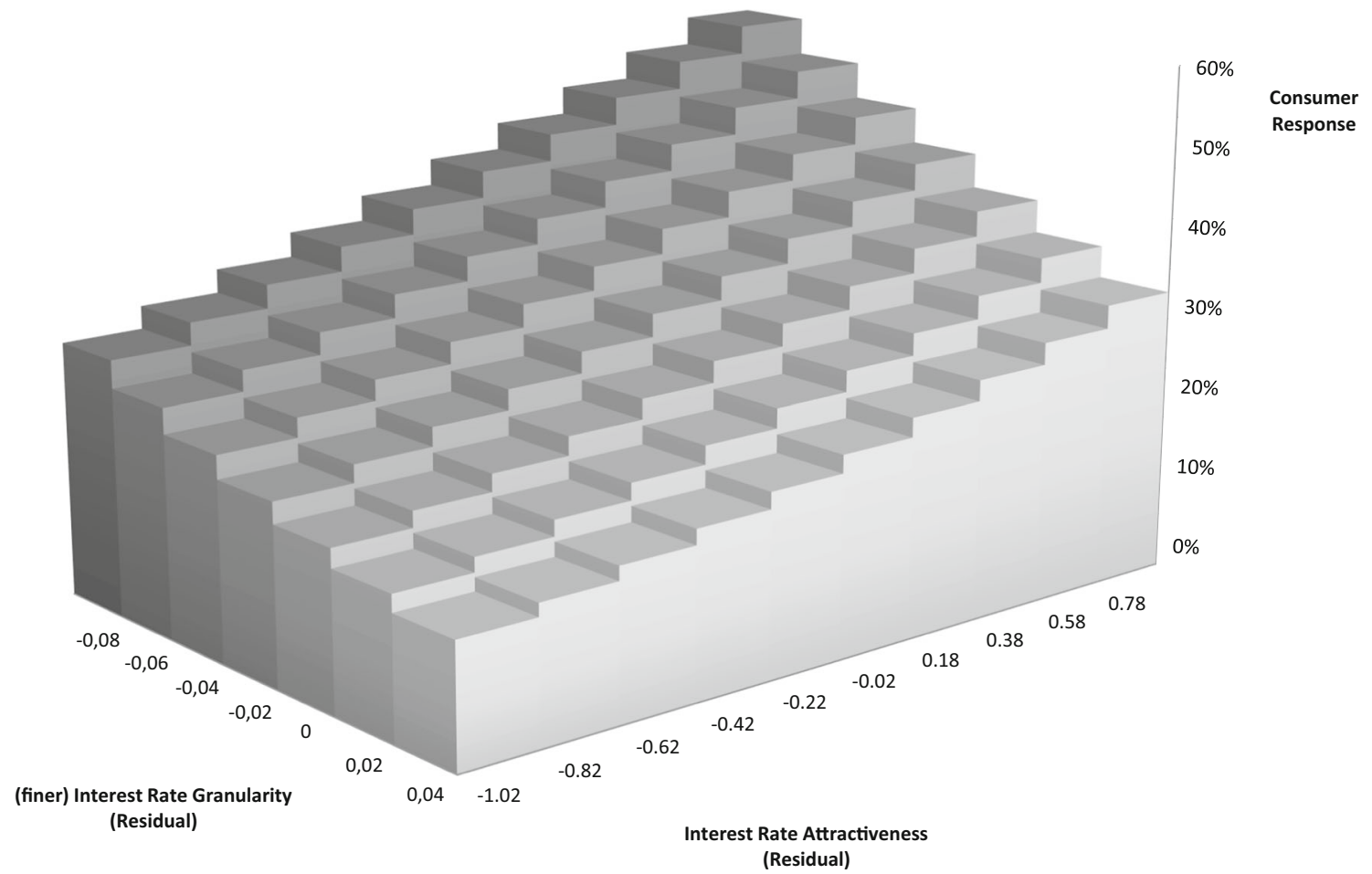

Fig. 2 Impact of (finer) interest rate granularity and interest rate attractiveness on consumer response

of how it affects consumer response. To examine the magnitude and practical importance of finer product set granularity on consumer response, we calculate the probability of consumer response when product set granularity-controlling for the most attractive product in the list-increases in coarseness by 0.01 percentage points. This increase in coarseness causes an average increase of $6.36 \%$ in the probability of consumer response over all visits. A clear illustration of the effect of product set granularity is the impact on consumer response when granularity is made finer. We illustrate this impact by making the granularity 0.01 percentage points finer. Note that, normatively, this change renders the recommendation list more attractive as it implies that the worst of the set of top alternatives becomes more attractive. However, we see that making the set of top alternatives objectively more attractive in this manner reduces the probability of consumer response by an average of $6.12 \%$ across all recommendation lists. To further illustrate the impact of product set granularity: the firm would have to raise the attractiveness of the best product in the recommended set by $2.82 \%$ to achieve the same boost in consumer response caused by increasing the coarseness in the level of granularity in product attractiveness by 0.01 percentage points (see above). In other words, this implies that a reduction in the mortgage interest rate of 0.12 percentage points would be needed to induce the same increase in consumer response as an increase in coarseness of 0.01 percentage points could achieve. To translate this into economic implications for the firm, considering the fee per successful lead of the firm and using a rather conservative value for conversion rate from leads to sales, we find that an increase of 0.01 percentage points in coarseness in the product set granularity would lead to an annual increase of approximately 98,000 euro in the firm's revenue. Finally, we calculate how consumer response is affected by the removal of any one of the intermediate products in the list (i.e., position 2 to 8). By doing so, the most attractive product remains available in the recommended set, but by excluding one other alternative in the set, we increase the coarseness of the granularity in the set. We find that on average by removing any one of these products, the probability of consumer response increases by $2.63 \%$.

Not including highly attractive alternatives in a recommendation list raises ethical issues and might damage a website's reputation in the long term. Therefore, we advocate that the (predicted) most attractive product should always be presented to consumers. Keeping the best product constant, firms that increase the coarseness of the granularity of the total product set can effectively assist consumers in identifying that most attractive alternative among all alternatives 
included in the recommendation list. Then, given that our findings predict that consumers are more likely to choose the best product with a less fine-grained recommendation set, consumer welfare should improve (and the firm's reputation should also be improved). This practice can be realized if a well-designed algorithm is available to generate product recommendations which also received accurate information about consumers' preferences as input. Thus, this structure of the recommendation set represents a rather benevolent nudge to its users given that its impact is that consumers are more likely to choose the best alternative in the set.

The results reported here are especially relevant for product recommendation websites because they often operate as intermediaries and do not have direct control over the design and attributes of the products that they can recommend (e.g., price, product features). Intermediaries, however, do have the possibility to control which of the total set of available products to include when constructing a recommended set. Thus, product recommendation websites have greater control over the product granularity in the set of products presented in a recommendation than over the attractiveness level of the most attractive products in the market (which depends on what products are offered by manufacturers and service providers). Therefore, they can use changes in product set granularity to promote consumer response.

Our research also shows that measures of online information processing time offer valuable insights to predict consumer response to recommendations. The timebased results also suggest that merely increasing the duration of a consumer's visit to a recommendation website need not have a positive effect on consumer response. The impact strongly depends on how this time is allocated. Spending more time may, in fact, have a negative impact on consumer response when it involves extensive set level processing, reflecting the consumer's challenge in identifying their preferred alternative.

\section{Limitations and further research}

We see several promising avenues for future research. First, the analysis of the field data is restricted to visits on the site that accessed only one recommended set. When consumers face multiple recommendation lists, defining product set granularity becomes more intricate as it may vary between different sets that a consumer observes. In this case, a consumer's memory for product information from a previously observed set could play a role in response to a current set.
Although we found a negative effect of finer granularity on consumer response, we also caution against dismissing the possibility that sets with unattractive alternatives alongside attractive ones (i.e., much coarser product set granularity) can also, in some instances, have a negative effect on consumer response. In particular, one could imagine that if websites provided recommendation lists including substantially worse products, the low attractiveness of such products might lead consumers to ignore them completely in their decision making. In such a case, increasing product set granularity coarseness might become ineffective because the very unattractive products would be eliminated from consideration and hence not affect consumer response. Further research could investigate such extreme recommendation sets with highly unattractive products to determine empirical boundary conditions to our findings. Coarser granularity could also lead to consumer concerns about the quality or unbiasedness of the recommendations. Therefore, it would be interesting to examine the effects of (finer vs. coarser) product set granularity on consumer trust towards the website's recommendations. Alternatively, consumers who put greater effort in choosing from a finegrained set may feel dissatisfied by the increased cognitive resources they put in (Klein and Yadav 1989), yet may feel satisfied due to their higher engagement in the task (Norton et al. 2012). Future research could investigate if consumer trust and satisfaction can serve as mediators of our conceptual model of product set granularity.

Interestingly, with current advances, many recommender systems attempt, using machine learning algorithms, to predict consumer behavior and recommend products to consumers based on other consumers' choice behavior. It is an interesting question whether the use of machine learning algorithms (instead of expert review scores) would change our findings. We expect that this may indeed be the case and that it may undesirable to use machine learning only in the type of recommendation environments that we study. The reason for incorporating experts' advice is that consumer may be harmed if they only follow their own judgments (or machine learning algorithms that are only based on other consumers' judgment) because of the complexity of the financial product. From a learning optimization perspective, it also interesting that, once consumers are provided with expert advice, their choices become co-determined by this advice, such that machine learning algorithms would learn about some (unknown) mix of consumer preference for product attributes and for following the expert advice. Firms then need to develop a strategy to disentangle these two decision components and a policy on how much they would wish to allow consumers to deviate from (objectively superior) expert advice. 
Information search patterns may differ based on the nature of the product searched (Chernev et al. 2015; Huang et al. 2009). In the empirical applications, we provide generalizable evidence in the context of utilitarian and search products, where decision engagement is central. It is interesting to investigate how closely our findings generalize to product categories of a more hedonic nature, where alternatives vary more in terms of experiential aspects, quality-related attributes are more important, and product set granularity of recommended products may thus be less obvious. Further, a promising avenue for research would be to examine the effect of product set granularity in product sets with different levels and sources of complexity. Previous research suggests that the nature of attributes characterizing the products can affect consumer response in various directions (Chernev 2005; Gourville and Soman 2005). Finally, while the effect of product set granularity on the decision of consumers to make a purchase decision is central to firms (Davis 2018; Dhar 1997), it would be interesting to extend this study by combining it with insights from research that examines how choice set features influence which specific product consumers choose (Chernev 2005; Simonson and Tversky 1992).

\section{Conclusion}

We investigated the effect of product set granularity in recommendations on consumer response. While product recommendations help consumers identify more attractive products when assortments are fine-grained, they also amplify the challenge of selecting one's preferred alternative due to the increased closeness in attractiveness of the recommended products which increases decision difficulty. We show in two studies that finer product set granularity indeed decreases the probability of consumer response to product recommendations. This effect is mediated by the relative time consumers spend processing information at the level of individual alternatives in the recommendation list. These effects are pronounced when consumer engagement in the decision process is relatively high. Our findings have important managerial implications for the composition of the recommended sets in terms of fine product set granularity. We show that minor shifts in the product set granularity can have substantial effects on the firm's profitability.

Acknowledgments We thank Netspar for financial support for part of this research to the first, second and third author. We also thank Mieke van Os at Independer.nl for providing us with the field data used in this research and for practical insights on the recommendation website's structure. We thank Susan Woodward and other participants at the Boulder Summer Conference on Consumer Financial Decision Making for valuable feedback on an earlier version of this paper.

\section{Appendix 1}

Table 4 Descriptive statistics and control variables

\begin{tabular}{|c|c|c|c|c|}
\hline Variable & Mean & Median & Min & Max. \\
\hline \multicolumn{5}{|l|}{ Recommended Set Properties } \\
\hline Interest Rate attractiveness (lowest) & 4.31 & 4.40 & 2.70 & 5.65 \\
\hline Interest Rate Granularity & -0.03 & -0.03 & -0.14 & -0.01 \\
\hline Product Rating Attractiveness (highest) & 3.02 & 3.00 & 3.00 & 4.00 \\
\hline Product Rating Granularity & -0.11 & 1.00 & -0.22 & 0.00 \\
\hline Provider Rating Attractiveness (highest) & 7.11 & 7.20 & 6.39 & 7.22 \\
\hline Provider Rating Granularity & -0.13 & 1.20 & -0.15 & -0.00 \\
\hline Attribute correlation & -0.06 & -0.09 & -0.84 & 0.73 \\
\hline \multicolumn{5}{|l|}{ User Time (in seconds) } \\
\hline TimeSet & 133.7 & 69 & 10 & 2924 \\
\hline TimeProduct* & 119.1 & 78 & 1 & 4286 \\
\hline Ratio Product Time & 0.54 & 0.69 & 0 & 0.99 \\
\hline \multicolumn{5}{|l|}{ Control Variables } \\
\hline Fixed Period Disclosed & 0.79 & 1.00 & 0 & 1 \\
\hline Fixed Period & 8.60 & 10.00 & 0 & 30 \\
\hline Admin Fee & 1.36 & 2.00 & 0.00 & 2.00 \\
\hline Income Disclosed & 0.99 & 1.00 & 0 & 1 \\
\hline Income $^{(\mathrm{L})}$ & 10.68 & 10.67 & 0 & 18.37 \\
\hline Amount Disclosed & 0.82 & 1.00 & 0 & 1 \\
\hline Amount $^{(L)}$ & 9.98 & 12.12 & 0 & 16.98 \\
\hline Mortgage Type & 1.51 & 2.00 & 0 & 2 \\
\hline Weekend & 0.83 & 2.00 & 0 & 1 \\
\hline Hour & 15.28 & 2.00 & 0 & 24 \\
\hline Brand included in the set & \multicolumn{2}{|c|}{$0.15-0.81$} & 0 & 1 \\
\hline Current Bank in the set & 0.19 & 0 & 0 & 1 \\
\hline
\end{tabular}

* Time given inspection; (D) Dummy variables, ${ }^{(\mathrm{L})}$ Natural Logarithm form of the variable; ${ }^{\wedge} 26$ brand dummy variables included

\section{Appendix 2: Overview of control variables included in the models}

The main variables of interest are product set attractiveness, product set granularity and the time processing variables. Next to these variables, we also include several other variables that capture properties of the top set of alternatives. First, we include the (inter-attribute) correlation between attractiveness (interest rate) and product/provider ratings among the top alternatives. A more negative inter-attribute correlation implies greater trade-off difficulty (Bettman et al. 1993; Johnson et al. 1989; Ordonez 1998) and this might also render consumers less likely to respond (Dhar 1997). We allow for this possibility by including the average of the pairwise correlations between interest rate and each of the two ratings among the top alternatives in the recommendation list (AttributeCorrelation). Second, we include two remaining variables to capture other possible impacts of set attractiveness. They are: (1) a dummy 
variable to indicate if the users' current bank is present among the top alternatives in the recommendation list (Current) and (2) the average administrative fee that was charged for the mortgage products in the set (AdminFee).

Finally, we include several variables that are not related to the recommended product set, but that may also impact consumer response. These include information consumers provided on the website before obtaining a recommendation. More precisely, we control for (a) whether a consumer disclosed his/ her income or not and his/her specified income, (b) whether a consumer disclosed the amount of the desired mortgage or not and the actual specified amount of the mortgage, (c) whether a consumer specified a period for a fixed interest rate or not and the specified period, and (d) the requested mortgage type. Further we control for whether different product providers were present in a product set (26 brand dummies). Finally, we control for the session's time of the day (at an hourly basis) and for the day of the week (weekend dummy).

\section{Appendix 3: Experiment - Interaction Effects}

We examined whether engagement with the decision process moderates the effect of granularity (Table 5 ). In line with the field evidence, we find that the negative effect of fine granularity is significant for consumers with high decision engagement ( $\beta=-1.54, p<0.05)$, but not with low engagement. We also find that the effect of finer granularity for the highly engaged consumers on consumer response is mediated by the ratio of product information processing time, and in the expected direction. Finer product granularity reduced the ratio of product versus product plus set level time for highly engaged consumers.
Open Access This article is distributed under the terms of the Creative Commons Attribution 4.0 International License (http:// creativecommons.org/licenses/by/4.0/), which permits unrestricted use, distribution, and reproduction in any medium, provided you give appropriate credit to the original author(s) and the source, provide a link to the Creative Commons license, and indicate if changes were made.

\section{References}

Anderson, C. J. (2003). The psychology of doing nothing: Forms of decision avoidance result from reason and emotion. Psychological Bulletin, 129(1), 139-167.

Bettman, J. R., \& Park, C. W. (1980). Effects of prior knowledge and experience and phase of the choice process on consumer decision processes: A protocol analysis. Journal of Consumer Research, 7(3), 234-248.

Bettman, J. R., Johnson, E. J., Luce, M. F., \& Payne, J. W. (1993). Correlation, conflict, and choice. Journal of Experimental Psychology: Learning, Memory, and Cognition, 19(4), 931-951.

Bettman, J. R., Luce, M. F., \& Payne, J. W. (1998). Constructive consumer choice processes. Journal of Consumer Research, 25(3), $187-217$

Broniarczyk, S. M., \& Griffin, J. G. (2014). Decision difficulty in the age of consumer empowerment. Journal of Consumer Psychology, 24(4), 608-625.

Bucklin, R. E., \& Sismeiro, C. (2003). A model of web site browsing behavior estimated on clickstream data. Journal of Marketing Research, 40(3), 249-267.

Busemeyer, J. R., \& Townsend, J. T. (1993). Decision field theory: A dynamic-cognitive approach to decision making in an uncertain environment. Psychological Review, 100(3), 432-459.

Chatterjee, S., \& Heath, T. B. (1996). Conflict and loss aversion in multiattribute choice: The effects of trade-off size and reference dependence on decision difficulty. Organizational Behavior and Human Decision Processes, 67(2), 144-155.

Table 5 Study 2 results
(1)
(2)
(3)

\begin{tabular}{|c|c|c|c|}
\hline & DV: Consumer Response (Logit) & DV: Ratio Product Time (OLS) & DV: Consumer Response (Logit) \\
\hline \multirow[t]{2}{*}{ Constant } & $1.67^{* *}$ & $0.49^{* *}$ & -0.69 \\
\hline & $(0.28)$ & $(0.02)$ & $(0.85)$ \\
\hline \multirow[t]{2}{*}{ (finer) Granularity } & 0.75 & $0.07^{*}$ & 0.32 \\
\hline & $(0.51)$ & $(0.03)$ & $(0.55)$ \\
\hline \multirow[t]{2}{*}{ Decision Engagement } & 0.59 & $0.10^{* *}$ & 0.05 \\
\hline & $(0.42)$ & $(0.03)$ & $(0.48)$ \\
\hline \multirow[t]{2}{*}{ Decision Engagement * (finer) Granularity } & $-1.54^{*}$ & $-0.12^{* *}$ & -0.92 \\
\hline & $(0.65)$ & $(0.04)$ & $(0.71)$ \\
\hline \multirow[t]{2}{*}{ Ratio $\left(\right.$ TimeProduct ${ }^{(\mathrm{L})} /\left(\right.$ Time $\left.(\text { Set }+ \text { Product })^{(\mathrm{L})}\right)$} & & & $5.17^{* *}$ \\
\hline & & & $(0.80)$ \\
\hline \multirow[t]{2}{*}{ TimeTotal $^{(\mathrm{L})}$} & & & 0.06 \\
\hline & & & $(0.19)$ \\
\hline$N$ & 399 & 399 & 399 \\
\hline Log likelihood / $\mathrm{R}^{2}$ & -152.99 & 0.04 & -128.20 \\
\hline
\end{tabular}

Coefficients are unstandardized; Standard errors in parentheses; ${ }^{*} p<.05,{ }^{* *} p<.01$; ${ }^{(\mathrm{L})}$ Natural Logarithm form of the variable; Results remain robust when we control for consumer demographics 
Chernev, A. (2005). Feature complementarity and assortment in choice. Journal of Consumer Research, 31(4), 748-759.

Chernev, A. (2006). Differentiation and parity in assortment pricing. Journal of Consumer Research, 33(2), 199-210.

Chernev, A., Böckenholt, U., \& Goodman, J. (2015). Choice overload: A conceptual review and meta-analysis. Journal of Consumer Psychology, 25(2), 333-358.

Danaher, P. J., Smith, M. S., Ranasinghe, K., \& Danaher, T. S. (2015). Where, when, and how long: Factors that influence the redemption of Mobile phone coupons. Journal of Marketing Research, 52(5), $710-725$.

Davis, B. (2018), What is a good ecommerce conversion rate?, https:// econsultancy.com/what-good-ecommerce-conversion-rateaverage/. Accessed 7 May 2019.

Dellaert, B. G. C., \& Häubl, G. (2012). Searching in choice mode: Consumer decision processes in product search with recommendations. Journal of Marketing Research, 49(2), 277-288.

Dellaert, B. G. C., Donkers, B., \& van Soest, A. (2012). Complexity effects in choice experiment-based models. Journal of Marketing Research, 49(3), 424-434.

Devlin, J. F. (2002). An analysis of choice criteria in the home loans market. International Journal of Bank Marketing, 20(5), 212-226.

Dhar, R. (1996). The effect of decision strategy on deciding to defer choice. Journal of Behavioral Decision Making, 9(4), 265-281.

Dhar, R. (1997). Consumer preference for a no-choice option. Journal of Consumer Research, 24(2), 215-231.

Dhar, R., \& Nowlis, S. M. (2004). To buy or not to buy: Response mode effects on consumer choice. Journal of Marketing Research, 41(4), $423-432$.

Diehl, K., \& Zauberman, G. (2005). Searching ordered sets: Evaluations from sequences under search. Journal of Consumer Research, 31(4), 824-832.

Diehl, K., Kornish, L. J., \& Lynch, J. G. (2003). Smart agents: When lower search costs for quality information increase price sensitivity. Journal of Consumer Research, 30(1), 56-71.

Fasolo, B., Hertwig, R., Huber, M., \& Ludwig, M. (2009). Size, entropy, and density: What is the difference that makes the difference between small and large real-world assortments? Psychology \& Marketing, 26(3), 254-279.

Fischer, G. W., Luce, M. F., \& Jia, J. (2000). Attribute conflict and preference uncertainty: Effects on judgment time and error. Management Science, 46(1), 88-103.

Gourville, J. T., \& Soman, D. (2005). Overchoice and assortment type: When and why variety backfires. Marketing Science, 24(3), 382395 .

Häubl, G., \& Murray, K. B. (2003). Preference construction and persistence in digital marketplaces: The role of electronic recommendation agents. Journal of Consumer Psychology, 13(1-2), 75-91.

Häubl, G., \& Trifts, V. (2000). Consumer decision making in online shopping environments: The effects of interactive decision aids. Marketing Science, 19(1), 4-21.

Häubl, G., Dellaert, B. G. C., \& Donkers, B. (2010). Tunnel vision: Local behavioral influences on consumer decisions in product search. Marketing Science, 29(3), 438-455.

Hayes, A. F. (2012), PROCESS: A versatile computational tool for observed variable mediation, moderation, and conditional process modeling. White Paper.

Huang, P., Lurie, N. H., \& Mitra, S. (2009). Searching for experience on the web: An empirical examination of consumer behavior for search and experience goods. Journal of Marketing, 73(2), 55-69.

Jacoby, J., Szybillo, G. J., \& Berning, C. K. (1976). Time and consumer behavior: An interdisciplinary overview. Journal of Consumer Research, 2(4), 320-339.

Janiszewski, C., \& Lichtenstein, D. R. (1999). A range theory account of price perception. Journal of Consumer Research, 25(4), 353-368.
Johnson, E. J., Meyer, R. J., \& Ghose, S. (1989). When choice models fail: Compensatory models in negatively correlated environments. Journal of Marketing Research, 26(3), 255-270.

Johnson, E. J., Bellman, S., \& Lohse, G. L. (2003). Cognitive lock-in and the power law of practice. Journal of Marketing, 67(2), 62-75.

Klein, N. M., \& Yadav, M. S. (1989). Context effects on effort and accuracy in choice: An enquiry into adaptive decision making. Journal of Consumer Research, 15(4), 411-421.

Komiak, S. Y., \& Benbasat, I. (2006). The effects of personalization and familiarity on trust and adoption of recommendation agents. MIS Quarterly, 30(4), 941-960.

Laroche, M., \& Taylor, T. (1988). An empirical study of major segmentation issues in retail banking. International Journal of Bank Marketing, 6(1), 31-48.

Lee, J., \& Hogarth, J. M. (1999). The price of money: Consumers' understanding of APRs and contract interest rates. Journal of Public Policy \& Marketing, 18(1), 66-76.

Li, S. S., \& Karahanna, E. (2015). Online recommendation systems in a B2C e-commerce context: A review and future directions. Journal of the Association for Information Systems, 16(2), 72-107.

Liang, T. P., Lai, H. J., \& Ku, Y. C. (2006). Personalized content recommendation and user satisfaction: Theoretical synthesis and empirical findings. Journal of Management Information Systems, 23(3), 4570 .

Liberman, N., \& Förster, J. (2006). Inferences from decision difficulty. Journal of Experimental Social Psychology, 42(3), 290-301.

Mantel, S. P., \& Kardes, F. R. (1999). The role of direction of comparison, attribute-based processing, and attitude-based processing in consumer preference. Journal of Consumer Research, 25(4), 335-352.

Mellers, B. A. (2000). Choice and the relative pleasure of consequences. Psychological Bulletin, 126(6), 910-924.

Moe, W. W. (2003). Buying, searching, or browsing: Differentiating between online shoppers using in-store navigational clickstream. Journal of Consumer Psychology, 13(1), 29-39.

Moyer, R. S., \& Bayer, R. H. (1976). Mental comparison and the symbolic distance effect. Cognitive Psychology, 8(2), 228-246.

National Mortgage Database (2016). A Profile of 2016 Mortgage Borrowers. Retrieved from https://www.fhfa.gov/ PolicyProgramsResearch/Programs/Documents/NMDB-technicalreport_6pt0_041818.pdf. Accessed 7 May 2019.

Norton, M. I., Mochon, D., \& Ariely, D. (2012). The IKEA effect: When labor leads to love. Journal of Consumer Psychology, 22(3), 453460.

Ordonez, L. D. (1998). The effect of correlation between price and quality on consumer choice. Organizational Behavior and Human Decision Processes, 75(3), 258-273.

Papies, D., Ebbes, P., \& van Heerde, H. (2017). Addressing endogeneity in marketing models, in Advanced Methods for Modelling Markets by Peter S.H. Leeflang, Jaap E. Wieringa, Tammo H.A. Bijmolt and Koen H. Pauwels (eds), Springer international publishing.

Payne, J. W., Bettman, J. R., \& Johnson, E. J. (1988). Adaptive strategy selection in decision making. Journal of Experimental Psychology: Learning, Memory, and Cognition, 14(3), 534-552.

Petrin, A., \& Train, K. (2010). A control function approach to endogeneity in consumer choice models. Journal of Marketing Research, 47(1), 3-13.

Pieters, R. (2017). Meaningful mediation analysis: Plausible causal inference and informative communication. Journal of Consumer Research, 44(3), 692-716.

Ratneshwar, S., Shocker, A. D., \& Stewart, D. W. (1987). Toward understanding the attraction effect: The implications of product stimulus meaningfulness and familiarity. Journal of Consumer Research, $13(4), 520-533$.

Riedl, R., Brandstätter, E., \& Roithmayr, F. (2008). Identifying decision strategies: A process-and outcome-based classification method. Behavior Research Methods, 40(3), 795-807. 
Shen, Q., \& Xiao, P. (2014). McDonald's and KFC in China: Competitors or companions? Marketing Science, 33(2), 287-307.

Shugan, S. M. (1980). The cost of thinking. Journal of Consumer Research, 7(2), 99-111.

Simonson, I., \& Tversky, A. (1992). Choice in context: Tradeoff contrast and extremeness aversion. Journal of Marketing Research, 29(3), 281-295.

Sismeiro, C., \& Bucklin, R. E. (2004). Modeling purchase behavior at an e-commerce web site: A task-completion approach. Journal of Marketing Research, 41(3), 306-323.

Tam, K. Y., \& Ho, S. Y. (2005). Web personalization as a persuasion strategy: An elaboration likelihood model perspective. Information Systems Research, 16(3), 271-291.

Terza, J. V., Basu, A., \& Rathouz, P. J. (2008). Two-stage residual inclusion estimation: Addressing endogeneity in health econometric modeling. Journal of Health Economics, 27(3), 531-543.
Tyebjee, T. T. (1979). Response time, conflict, and involvement in brand choice. Journal of Consumer Research, 6(3), 295-304.

Xiao, B., \& Benbasat, I. (2007). Consumer decision support systems for e-commerce: Design and adoption of product recommendation agents. MIS Quarterly, 31(1), 317-209.

Zhao, X., Lynch, J. G., Jr., \& Chen, Q. (2010). Reconsidering baron and Kenny: Myths and truths about mediation analysis. Journal of Consumer Research, 37(2), 197-206.

Publisher's note Springer Nature remains neutral with regard to jurisdictional claims in published maps and institutional affiliations. 